\title{
The Significance of Mobile Equipment for Network Education
}

\author{
Yingying Sun ${ }^{1}$, a \\ 'School of Information Technology and Media, Beihua University, Jilin, China 132013 \\ awsyy_9@126.com
}

\begin{abstract}
Keywords: Mobile device; Network education; Cultural value; Learning platform; Learning resources
\end{abstract}

\begin{abstract}
In recent years, with the rapid development of mobile communication technology and multimedia business, mobile devices have been widely used to influence and promote the continuous transformation of network education methods and style. The development of mobile equipment is of great significance to the development of network education. In view of the popularization of mobile devices and the rising of online education, this paper systematically expounded the relationship and significance of mutual promotion and mutual development between mobile devices and online education.
\end{abstract}

\section{The Concept of Online Education}

Since the 1980s, China's communications technology and computer network have made a rapid development, when the computer network development moved to around 2000, a completely new educational model different from the traditional education by virtue of modern network technology appeared, this is the network education.

Network education first appeared in the United States, after 1998, gradually widely popularized and developed in the world. China's online education is spread from North America and Western Europe, although in the last century, some families had used the computer in China, the penetration and utilization rate was still very low, the large-scale use of the computer appeared after 2000 . As China's computer gradually was popularized and used in the tens of thousands of households, online education in China began to gradually develop up. Maybe we also has some initial impression on the development stage of the network education, when we called it distance education, many well-known secondary schools such as Beijing Fourth Middle School, Huanggang Middle School, Beijing 101 Middle School set up distance education course that we called online education. At that time the number of applicants is great, but also to a lot of parents and students, they saw even if not in a good secondary school the students can be through the network education to face good teachers for the future exam and college entrance examination. At present, with the rapid development of the network and the formation of the local area network, in the process of teaching that traditional education, it also gradually using online education this emerging educational model and achieved very significant educational results. Online education currently includes many aspects, such as the basic network education of primary and secondary school network education, higher network education of university education, enterprise network education, network education with the characteristics and so on. Compared with traditional education, Online education has a lot of advantages, but also very obvious, for example, resource utilization of network education is high, there will be no waste of resources; less time and space constraints; management model is free and automatic ; Education model is more abundant and so on. The Chinese government in the early 21 st century introduced the "Action Plan for the 21st Century Education Revitalization" clearly indicated that "the implementation of modern education projects, to form an open education network, construct lifelong learning system." At present, China's online education has been basically built up, the state approved a number of colleges and universities have the network education qualifications, with a total of 68 colleges and universities at this stage, we can believe this scale will be increased in the future. 


\section{The Rapid Development of Mobile Devices in Recent Years}

Mobile devices include mobile phones, tablets, laptops, game consoles, personal digital assistants, and so on. In 2013, CNNIC released the "Internet Development Statistics Report": as of the end of 2012, the number of Internet users in China was 564 million, the Internet family penetration rate is $42 \%$. While the number of Chinese mobile phone customers in 2012 was 420 million, the growth rate is reached $18 \%$, far more than the increase in the number of Internet users, and now the largest mobile phone terminal size and mode has been formed, human beings have entered the mobile phone era. In recent years, the development of mobile devices is very fast, especially the popularity and development of smart phones is changing people's lives, the earth village is getting smaller and smaller, while smart phone features become stronger day by day. Now the smart phone, whether in the aspect of listening to the sound quality of music, camera pixels or browse the web speed have been greater improved than the previous few years, modern people have been inseparable from the ever-changing mobile devices. With the development of science and technology, the storage capacity of mobile devices is growing, a lot of books in ancient has been nothing, modern mobile equipment can load the entire library of books, you can not read all of them. We also believe that future mobile devices will have better development, and there will be more revolutionary progress and development.

\section{The Significance of Mobile Device for Online Education}

At present, there are a wide variety of platforms for mobile devices, and the selectivity is very large. But no matter how many types, the basic model of human-computer interaction and the principle of the user feeling experience will not change. Now mobile devices touchable and human-computer interaction have obtained a greater development, modern mobile device development view interface is also become more simple, convenient and at a glance, and even the elderly can also quickly grasp it. Simple operation has become a trend in the development of mobile devices. And it is the use of mobile devices, such as human interaction and simple operation, and so good performance, making the network education has a much better platform. Using handheld mobile devices to achieve a general sense of mobile learning, the combination of handheld mobile devices and online education with large-scale use break the time and space constraints, really realize to achieve the learning conditions no matter when or where, so that learners can take full advantage of fragmented time for targeted learning, can improve the efficiency of the use of time, breaking the integrity of the traditional education system, to change the learning concept.

First, human-computer interaction can effectively make the original boring network education becomes more lively, this advantage not only has a prompt role in children's online education learning, but also for students of higher education network education, it can also let them get rid of the general sense of too rigid too boring shortcomings in other equipment of the network education. Second, people can feel free to content choose according to their own interesting, conveniently and flexibly. Network education will be downloaded and installed through mobile devices and software programs, through the carrier to achieve the purpose of resource allocation optimization, and excellent resources of network education can also be more widely spread and development. The third point is that the development of mobile devices in the form of mobile learning is in mobile changes, that is, learners are not limited to learn rigidly in front of the computer, but can be free, in anytime or anywhere to learn the purpose and content with flexible choice according to the needs. Mobile learning is highly interactive in content, this advantage is more obvious than the traditional learning. Because the mobile learning technology is based on the combination of wireless and internet technology, then only in the content of interaction, to achieve two-way communication, so mobile learning is more meaningful in order to show the advantages of mobile learning. Fourth, the currently vigorous development of online education, its cultural value is bound to increase the added value of handheld mobile devices, online education and mobile devices are developing with the booming of computer and the internet, but the nature of education and the culture for the network education can help mobile devices increase the value-added products. There are many 
companies are making a big fuss, but not only did not establish a good corporate culture and corporate reputation, but counterproductive, in this aspect, Apple, from United States, has done very well, worthy of learning for some of the current business, if Apple users buy a new generation of Apple products, willing to donate the old products before the apple can go to the major stores, while the money from the donated Apple's old products will be used to support education activities, which not only can train a group of teachers, but also spread knowledge to the children in mountains, this action is meaningful, so that the company's image was widely appreciated in the community, showing promotion of the mobile device for the online education.

\section{References}

[1] Sun Yingying. Education information technology exploration and practice [J]. Education and Occupation, 2012 (11) 163-164

[2] Sun Yingying. Initial study on the relationship between information technology and modern educational technology [J]. China Education Technology \& Equipment, 2011 (09) 117-118 